\section{Degenerative effects in rat eyes after experimental ocular hypertension}

\author{
G. Scarsella, ${ }^{1}$ M. Nebbioso, ${ }^{2}$ S. Stefanini, ${ }^{1}$ \\ A. Librando, ${ }^{2}$ N. Pescosolido ${ }^{3}$ \\ 'Department of Biology and \\ Biotechnology Charles Darwin, Sapienza \\ University of Rome; \\ 2Department of Sense Organs, Sapienza \\ University of Rome; \\ ${ }^{3}$ Department of Cardiovascular, \\ Respiratory, Nephrologic and Geriatric \\ Sciences, Sapienza University of Rome, \\ Italy
}

\section{Abstract}

This study was used to evaluate the degenerative effects on the retina and eye-cup sections after experimental induction of acute ocular hypertension on animal models. In particular, vascular events were directly focused in this research in order to assess the vascular remodeling after transient ocular hypertension on rat models. After local anaesthesia by administration of eye drops of $0.4 \%$ oxibuprocaine, 16 male adult Wistar rats were injected in the anterior chamber of the right eye with $15 \mu \mathrm{L}$ of methylcellulose (MTC) $2 \%$ in physiological solution. The morphology and the vessels of the retina and eye-cup sections were examined in animals sacrificed $72 \mathrm{~h}$ after induction of ocular hypertension. In retinal fluorescein angiographies (FAGs), by means of fluorescein isothiocyanate-coniugated dextran (FITC), the radial venules showed enlargements and increased branching, while the arterioles appeared focally thickened. The length and size of actually perfused vessels appeared increased in the whole superficial plexus. In eye-cup sections of MTC-injected animals, in deep plexus and connecting layer there was a bigger increase of vessels than in controls. Moreover, the immunolocalization of astrocytic marker glial fibrillary acidic protein (GFAP) revealed its increased expression in internal limiting membrane and ganglion cell layer, as well as its presence in Müller cells. Finally, the pro-angiogenic factor vascular endothelial growth factor (VEGF) was found to be especially expressed by neurones of ganglion cell layer, both in control and in MTCinjected eyes. The data obtained in this experimental model on the interactions among glia, vessels and neurons should be useful to evaluate if also in glaucomatous patients the activation of vessel-adjacent glial cells might play key roles in following neuronal dysfunction.

\section{Introduction}

Increase of intra-ocular pressure (IOP) is generally recognized as the main cause of glaucoma. ${ }^{1}$ In fact, the ocular hypertension damages the retinal ganglion cells (RGCs) causing apoptotic death. ${ }^{2}$ In previous researches some authors described the degenerative and apoptotic events induced in adult rats by the IOP increase caused by inoculation of methylcellulose (MTC) in the anterior chamber. ${ }^{3}$ Being an approachable part of the brain, the retina provides a highly valuable system to investigate the relationships between neurons, glia and vessels. During embryogenesis the maturation of vessels is linked to the oxygen local tension and it is interconnected to the development and the guidance of neuronal, horizontal and astrocytic laminae. These specific spatial relationships are even maintained in adult animals. ${ }^{4}$ In retina the glial cells, which give structural and functional support to neuronal fibers, are especially susceptible to ischemic or mechanic insults. In particular, the expression of glial fibrillary acidic protein (GFAP) in astrocytes and Müller cells is considered as an indicator of stress by means of axonal damage. Dramatic changes of GFAP expression were described in retina detachment, ${ }^{5,6}$ diabetic retinopathy, ${ }^{7}$ age-related macular degeneration, ${ }^{8}$ and glaucoma ${ }^{9-11}$ as well as in animal models of human pathologies, ${ }^{12-14}$ and in other experimental conditions. ${ }^{15-17}$ In glaucoma the production of neurotoxic and pro-apoptotic agents may affect neuronal microenvironment ${ }^{18-21}$ so as the persistence of glial activation might induce further degeneration of ganglion cells. ${ }^{22}$ On the other hand, the hypoxia-induced vascular endothelial growth factor (VEGF) plays key roles during angiogenesis. ${ }^{23-25}$ In retina, VEGF production by glial cells is related to vessel growth not only throughout normal development, ${ }^{26,27}$ but even during neovascularization that occurs in natural and experimental retinopathies..$^{28-31}$ In fact, in aqueous humour of patients affected by glaucoma higher concentrations of VEGF than in controls were also detected. ${ }^{32}$ VEGF thus appears to function in a paracrine fashion in developing retina, secreted by microglia and acting on nearby vasculature. The levels of hyperoxia suppressing vessel formation in the developing retina also suppress VEGF expression by astrocytes and Müller cells, respectively. ${ }^{26}$ Purpose of this study was to evaluate the degenerative effects on the retina and eye-cup sections after experimental induction of acute ocular hypertension on animal models. In particular, in this research vascular events were directly focused in order to assess the vascular remodeling after transient ocular hypertension. The morphology and the vessels of the
Correspondence: Dr. Marcella Nebbioso, Department of Sense Organs, Centre of Ocular Electrophysiology, viale del Policlinico 155, 00161 Rome, Italy.

Tel: +39.06.49975422 - Fax: +39.06 .49975425 .

E-mail: marcella.nebbioso@uniromal.it

Key words: angiogenesis, Bandeira simplicifolia isolectin $\mathrm{B}_{4}$ labelling, Glaucoma, Glial fibrillary acidic protein immunolocalization, VEGF immunolocalization.

Conflict of interest: the authors declare no conflict of interests.

Received for publication: 28 May 2012.

Accepted for publication: 12 September 2012.

This work is licensed under a Creative Commons Attribution NonCommercial 3.0 License (CC BYNC 3.0).

() Copyright G. Scarsella et al., 2012

Licensee PAGEPress, Italy

European Journal of Histochemistry 2012; 56:e42 doi:10.4081/ejh.2012.e42

retina and eye-cup sections were examined in rats sacrificed $72 \mathrm{~h}$ after induction of ocular hypertension. We also wanted to determine the total length and total area of actually perfused vessels, while in eye-cup sections labelled with the endothelial marker Bandeira simplicifolia isolectin $B_{4}\left(\mathrm{IB}_{4}\right)$, we counted retinal vessels belonging to different vascular plexuses. Besides, GFAP was immunolocalized in eye-cup sections from control and MTCinjected rats so as VEGF was immunolocalized both in eye-cup sections and in whole-mounted retinas.

\section{Materials and Methods}

\section{Animals and treatments}

All experimental procedures were in accordance with the ARVO statement for the use of animals in ophthalmic and vision research, the guidelines of the European Communities Council Directive of $24^{\text {th }}$ November 1986 (86/609/EEC), the Italian Health Ministry guidelines, and the EU Directive 2010/63/EU for animal experiments.

Sixteen male adult Wistar rats (average weight: $300-350 \mathrm{~g}$ ) were housed in controlled light and temperature. After local anaesthesia by administration of eye drops of $0.4 \%$ oxibuprocaine, animals were injected in the anterior chamber of the right eye with $15 \mu \mathrm{L}$ of MTC $2 \%$ in physiological solution. The controlateral sham-operated eyes were injected with physiological solution. The IOP was monitored by 
tonometry (Tonopen XL, Automated Ophthalmics, Ellicott City, MD, USA). The degree of animal sufferance was evaluated by the behavioural Irwin test and by the recovery of body weight. The ocular inflammation was assessed by the Draize test adapted to the rat.

\section{Fluorescein angiography}

Seventy two hours after intraocular injection, six of these animals were anaesthetized with general anaesthesia by intra-peritoneal injection of $500 \mu \mathrm{L}$ of Farmotal 5\% in phosphate buffered saline (PBS) and injected through the left ventricle with $2 \mathrm{~mL}$ of fluorescein isothiocyanate-conjugated dextran (FITC) 5\% in PBS. ${ }^{33}$ Following heart resection, eyes were enucleated and prefixed in $4 \%$ paraformaldehyde for $2 \mathrm{~h}$ at $4^{\circ} \mathrm{C}$. A suture was made on the eye at the 12 o'clock position to determine orientation. After careful dissection of cornea, lens, hyaloid vessels and vitreous humour from the inner surface, sclera and choroid from the outer surface, the isolated retinas underwent radial incision, by which 4 triangular regions were obtained, and overnight post fixation. Fluorescein angiographies (FAGs), from MTC-injected and shamoperated eyes, were examined by fluorescence (Zeiss Axioskop, Carl Zeiss Microscopy GmbH, Jena, Germany) microscopy. Each of the triangular regions was divided into four zones (adjacent, proximal, mid-peripheral and farperipheral) with respect to the optic nerve head. In each of these zones, the total length and the total area of vessels belonging to the superficial plexus, as well as the area of the region itself were measured. Other FAGs from 4 MTC-injected and 4 control eyes were used for VEGF labelling on whole mount retinas. Retinas were rinsed and incubated with PBS containing $1 \%$ normal mouse serum, $1 \%$ bovine serum albumin (BSA) and $0.5 \%$ Triton $\mathrm{X}-100$, overnight at $4{ }^{\circ} \mathrm{C}$. After that they were rinsed again with $\mathrm{PBS}$ and incubated with mouse monoclonal VEGF antibody 1:75 in PBS with $1 \%$ BSA and $0.5 \%$ Triton X-100, for 5-6 h at RT. Further, specimens were labelled with rhodamine-conjugated goat anti-mouse IgG 1:200 in PBS with 1\% normal goat serum, for $30 \mathrm{~min}$ at RT. For negative control, primary antibody was omitted.

\section{Immunohistochemistry and IB4 labelling}

Seventy two hours after intraocular injection six animals, anaesthetized as above, underwent eye enucleation. Obtained eyes were prefixed for $2 \mathrm{~h}$ in $4 \%$ paraformaldehyde, the lenses were removed and the eye-cups were overnight postfixed, soaked in $30 \%$ saccharose for $2 \mathrm{~h}$, embedded in cryostatic medium and sagittally sectioned $(10 \mu \mathrm{m})$, parallel to
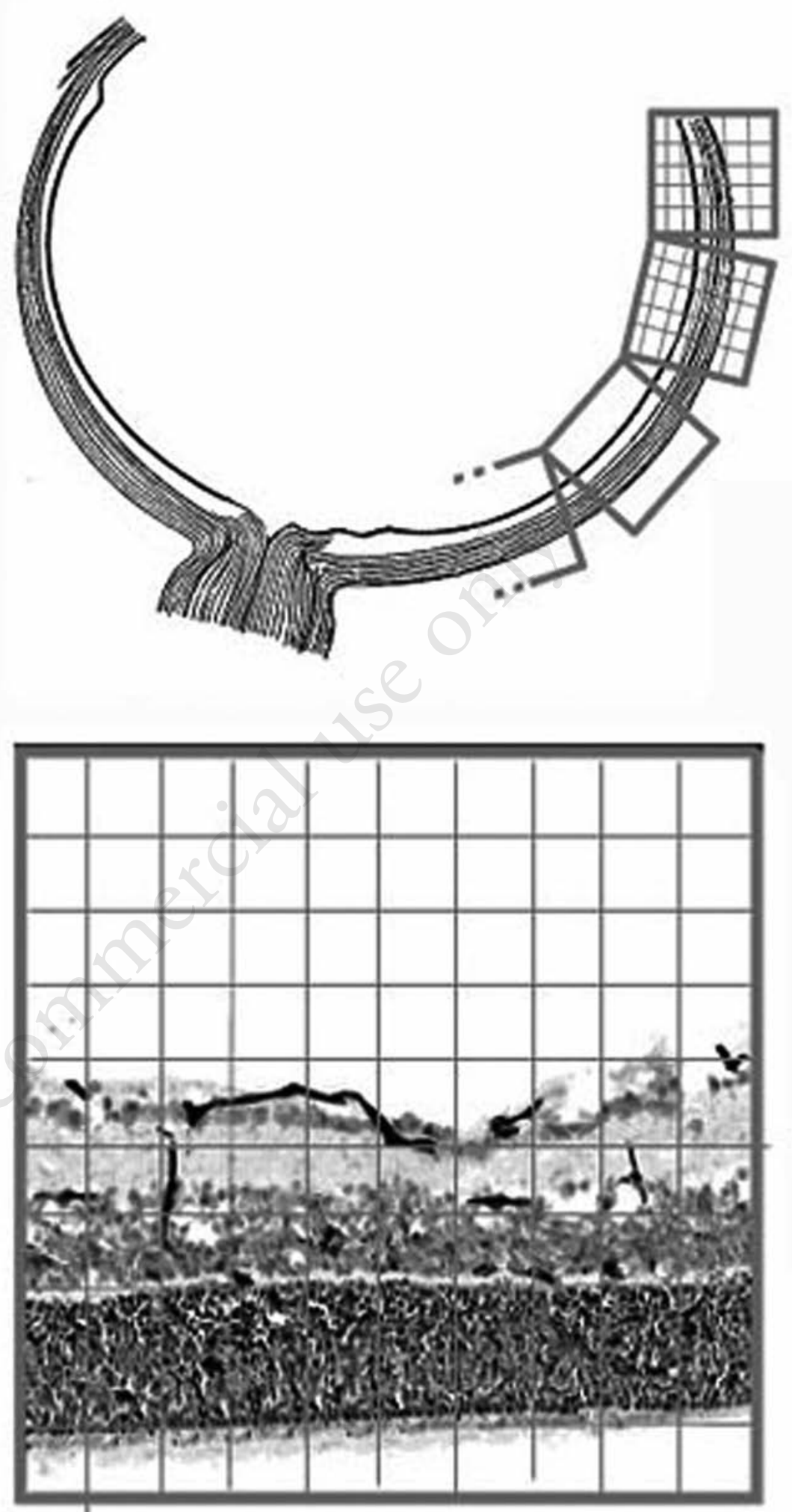

Figure 1. Procedure used to count vessel profiles in eye-cup sections labelled with isolectin B4. The values obtained from all retinal segments were used to evaluate statistical analysis. In each eye-cup, five IB4-labelled sections (parasagittal, mid-peripheral and farperipheral in the nasal side; mid-peripheral and far-peripheral in the temporal side) were examined with the aid of a grid located in the eyepiece of the microscope. The retinal surface was divided in 1-mm-long segments, in which the vessels belonging to the superficial plexus, the connecting layer and the deep plexus were separately counted. Vessels extended in two layers were counted in both of them. 
the vertical meridian plane.

For GFAP, VEGF, and HIF-1 immunolocalization, sections were processed as follows:

- Alcohol post-fixation $\left(70^{\circ}, 95^{\circ}, 100^{\circ}\right)$ for 2 min each;

- Normal mouse serum 1\% in PBS;

- Mouse monoclonal anti-VEGF 1:100, or mouse monoclonal anti-GFAP 1:200 in PBS with $1 \%$ BSA, for $1 \mathrm{~h}$ at RT;

- 1:200 diluted rhodamine-conjugated goat anti-mouse IgG, in PBS added with 1\% normal goat serum, for 30 min at RT.

For negative control, primary antibody was omitted.

For isolectin-labelling of vascular endothelium, sections were processed as follows:

Alcohol post-fixation for $2 \mathrm{~min}$;

1:25 diluted biotinylated $\mathrm{IB}_{4}$, in PBS added with $1 \% \mathrm{BSA}$, for $1 \mathrm{~h}$;

- $\mathrm{H}_{2} \mathrm{O}_{2} 0.3 \%$ in PBS, for 20 min, to inactivate endogenous peroxidases;

- Standard avidin-biotin-horseradish peroxidase complex for $30 \mathrm{~min}$;

- 0.05\% 3.3'-diaminobenzidine in PBS containing freshly added $0.01 \% \mathrm{H}_{2} \mathrm{O}_{2}$ for 2-5 min;
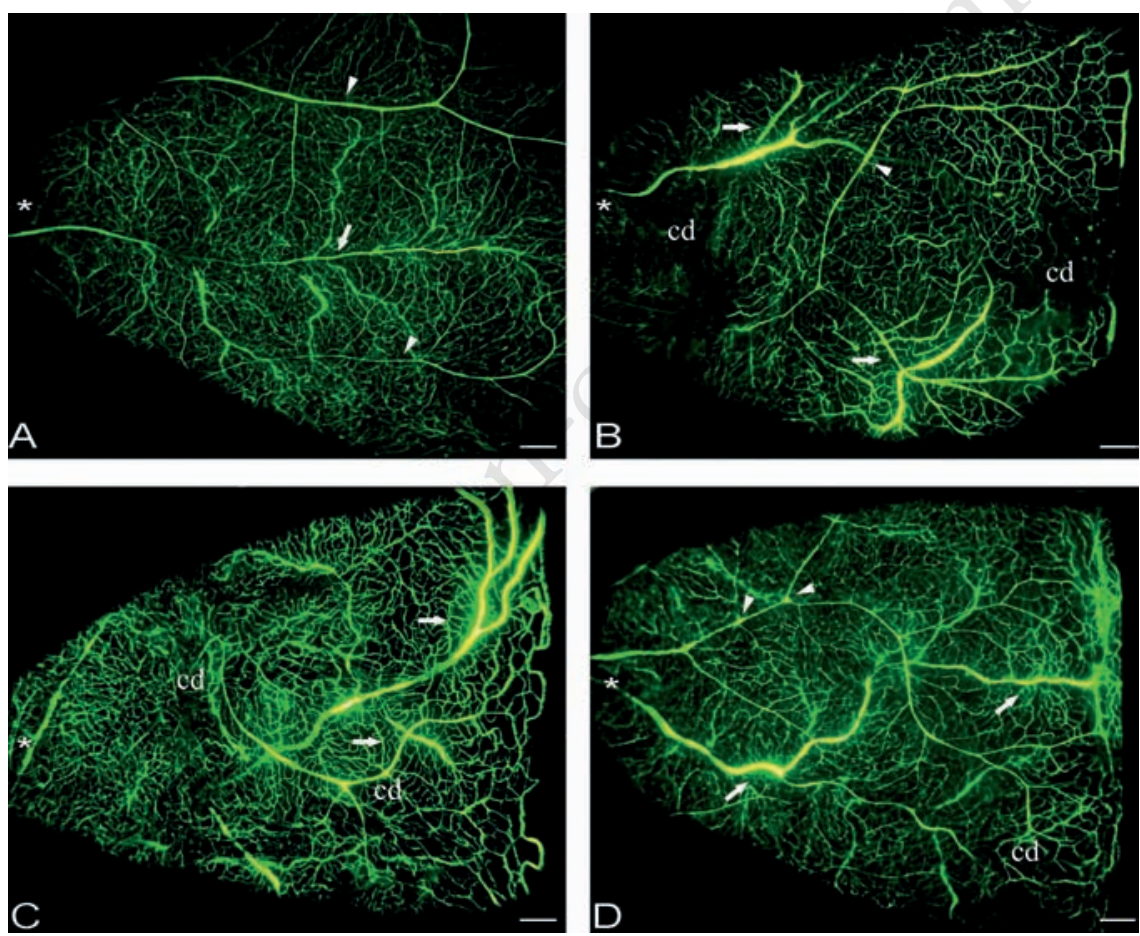

Figure 2. Retinal fluorescein angiographies (FAGs). 5x objective, focused on the superficial vascular plexus. Scale bar: $200 \mu \mathrm{m} .{ }^{*}$ = optic nerve head. A) Control rat. The radial arterioles (arrowheads), thin and straight, and the thicker radial venule (arrow) are normally perfused and the capillaries are uniformly present all around the main vessels. B-D) Treated rat. All radial venules appear abnormally dilated and branched, both in mid- and in far retinal periphery (arrows). Some radial arterioles show focal points of fluorescein isothiocyanate-coniugated dextran (FITC) thickening (arrowheads). The capillary net is coarser than normal and capillary-devoid regions $(c, d)$ are present. The non-vascular regions are dark and the margins and shapes are focused by means of arrows and arrowheads (c, d).
Haematoxylin counterstaining.

In each eye-cup, five $\mathrm{IB}_{4}$-labelled sections (parasagittal, mid-peripheral and far-peripheral in the nasal side; mid-peripheral and farperipheral in the temporal side) were examined with the aid of a grid located in the eyeof the microscope. The retinal surface the vessels the connecting layer and the deep plexus were separately counted. Vessels extended in two layers were counted in both of them (Figure 1). The values obtained from all the retinal segments were used to evaluate statistical analysis.

\section{Statistics}

For each morphometric parameter, variation coefficients were calculated and the signifivalues was evaluated by means of variance analysis (ANOVA).

\section{Chemicals}

Aldrich Srl (Milano, Italy); mouse monoclonal anti-GFAP antibody and 3,3'-diaminobenzidine were from Sigma Chemical Co. (Schnelledorf, Germany); mouse monoclonal anti-VEGF antibody was from Santa Cruz Biotechnology (Heidelberg, Germany); mouse monoclonal anti HIF-1 $\alpha$ antibody was from BD Bioscience (Milano, Italy); biotinylated IB4 and standard avidin-biotin-horseradish peroxidise complex were from Vector Laboratories (Burlingame, CA, USA); rhodamine-conjugated goat anti-mouse IgG antibody was from Molecular Probes (Eugene, OR, USA).
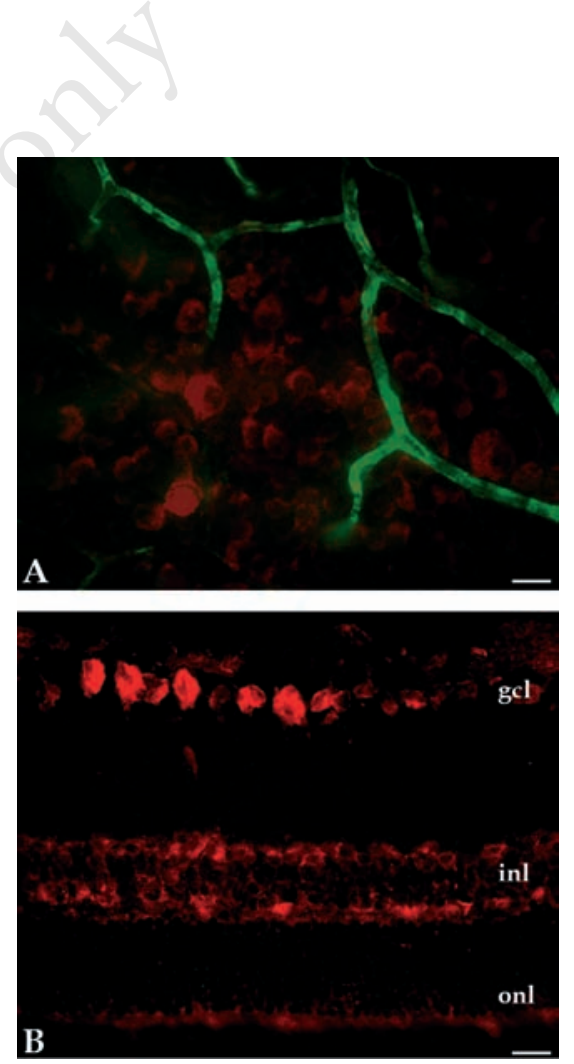

Figure 3. Vascular endothelial growth factor (VEGF) immunolocalization in rat retina. Scale bar: $100 \mu \mathrm{m}$. A) Fluorescein angiography (FAG). 40 x objective, focused on the superficial vascular plexus. Immunoreactivity is restricted to the cytoplasmic compartment of large cells, apparently located in a single layer, presumably ganglion cells. Some fluorescein isothiocyanate-coniugated dextran (FITC) containing vessels of superficial plexus are also visible. B) Eye-cup section. Gcl: ganglion cell layer; inl: inner nuclear layer; onl: outer nuclear layer. Cytoplasmic compartments of ganglion cells are heavily labelled; immunostaining is also present in inner nuclear and, at lower level, in outer nuclear layers. 


\section{Results}

The retinal FAGs obtained from sham-operated eyes (Figure $2 \mathrm{~A}$ ) showed radially oriented arterioles and venules, whose size did not change across length, and regularly arranged superficial and deep capillary nets. In retinal FAGs of MTC-treated animals radial venules appeared heavily altered. Branching and enlargement especially affected the midperipheral and far-peripheral retinal zones and extremely dilated vascular segments were often found close to retinal boundary. The arterioles generally maintained their normal size, but in many of them the FITC showed focal points of thickening. Capillary net was coarser than in controls and non-vascularized regions were found especially at the boundary between the proximal retinal periphery and the optic nerve-adjacent zone (Figures 2 B,C,D). Moreover, intra-vitreous vascular extensions or FITC leakage were never observed.

After incubation with anti-VEGF antibody, many large, strongly immunoreacting neurons, apparently located in a single layer, were visu-
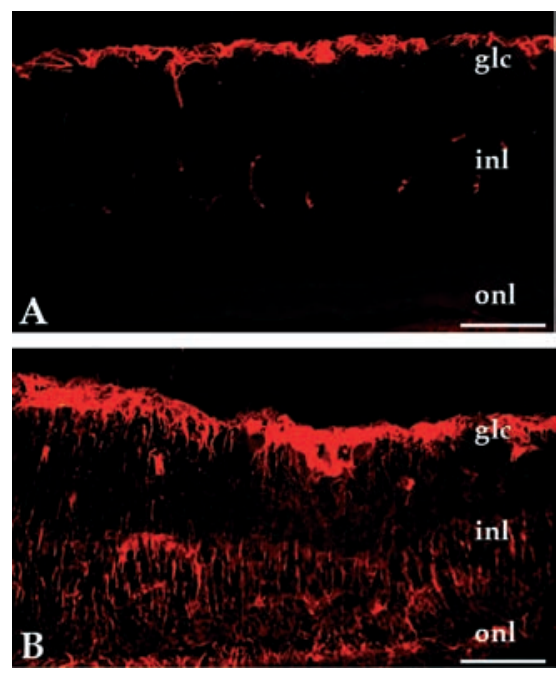

Figure 4. Glial fibrillary acidic protein (GFAP) immunolocalization in eye-cup sections. Scale bar: $100 \mu \mathrm{m}$. Gcl: ganglion cell layer; inl: inner nuclear layer; onl: outer nuclear layer. A) Control rat. A heavy labelling is found in the internal limiting membrane and ganglion cell layer. Very scarce staining is present in inner and outer nuclear layer. B) Treated rat. Labelling is especially abundant in internal limiting membrane and ganglion cell layer but immunoreacted cells are also visible in inner and outer nuclear layers; heavily immunoreacted cellular expansions, orthogonal to retinal surface, spread from internal limiting membrane up to photoreceptor layer. alized (Figure $3 \mathrm{~A}$ ) and identified as ganglion cells. This identification was confirmed in eyecup sections, where a strong immunoreactivity was found in the cytoplasmic compartment of ganglion cells, while the inner nuclear layer showed a milder positivity and the outer nuclear one was only faintly labelled. However, in the inner layer it was not possible to discriminate between different neuronal populations and Müller cells (Figure $3 \mathrm{~B}$ ).

In sections incubated for GFAP immunolocalization, positivity was only present in astrocytes of ganglion cell layer (Figure $4 \mathrm{~A}$ ). After incubation with anti GFAP antibody, the internal limiting membrane and ganglion cell layer showed a stronger increase of positivity compared to the control (Figures 4 A, B). Moreover, specific labelling was also present in the other retinal layers and heavily immunoreacted cellular expansions (perpendicularly oriented with respect to retinal surface) were frequently found to spread till photoreceptor layer (Figure 4 B). In FAGs of control eyes the mean area of retinal vessels measured in $1 \mathrm{~mm}^{2}$ of retinal surface was $0.11 \pm 0.05,0.13 \pm 0.03$, and $0.06 \pm 0.03 \mathrm{~mm}^{2}$ in the proximal, mid and far-
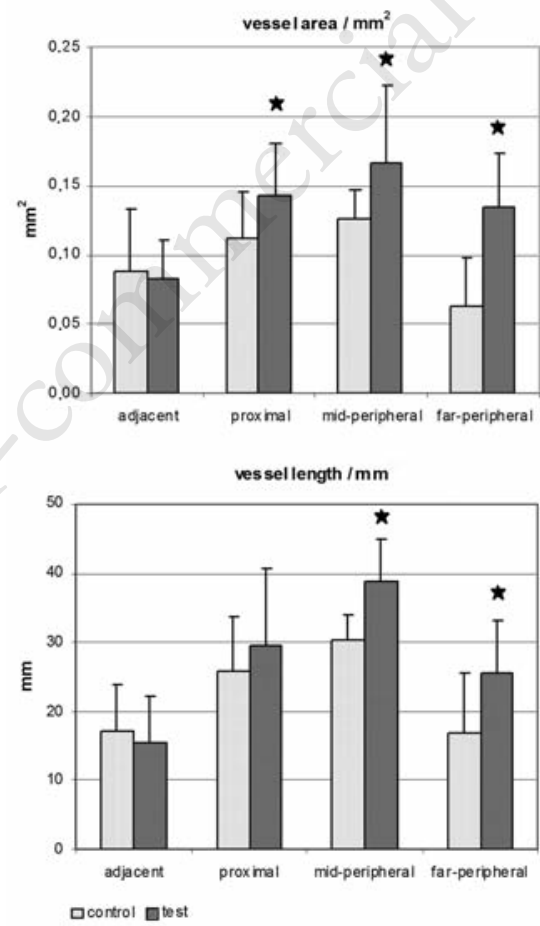

Figure 5. Dextran fluorescein isothiocyanate-coniugated dextran (FITC)-containing vessels of superficial plexus in retinal fluorescein angiographies (FAGs) from adult rats. Vessel area and vessel length are referred to $1 \mathrm{~mm}^{2}$ of retinal surface. Values are means \pm SD of individual values obtained in FAGs taken from MTC-treated (test) and control eyes. ${ }^{*}=$ Significantly different from the corresponding control $(\mathbf{P}<0.01)$.

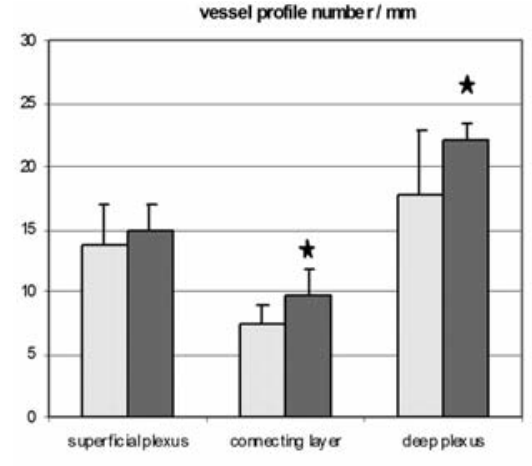

口ortrol घtest

Figure 6. Vessel profiles in eye-cup sections of adult rats labelled with isolectin $B_{4}$. Vessel profile number is referred to 1 mm-long segment of the sectioned retina. Values are means \pm SD of individual values obtained from MTC-treated (test) and control eyes. ${ }^{*}=$ Significantly different from the corresponding control $(P<0.01)$.
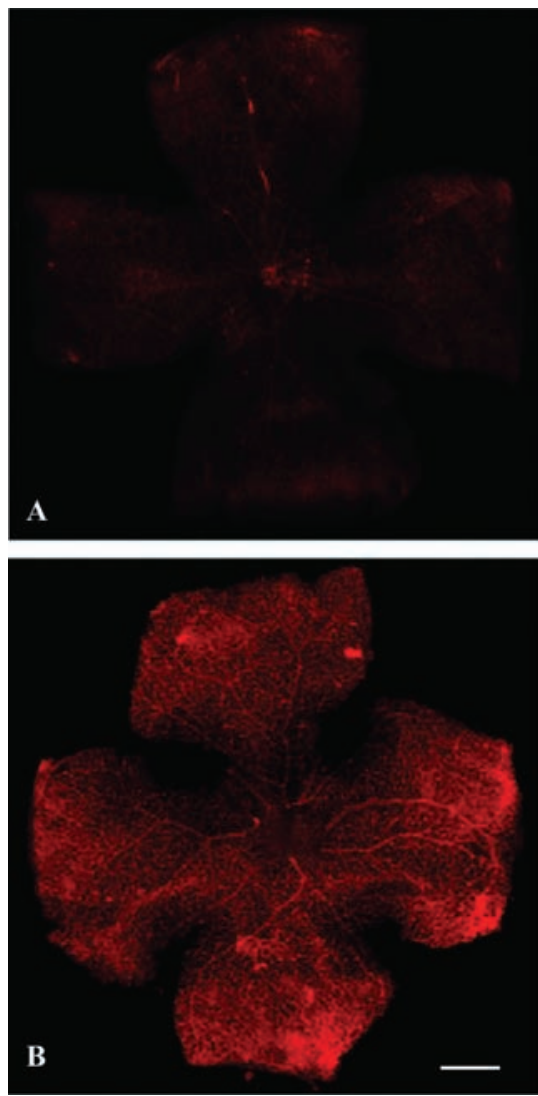

Figure 7. Immunolocalization of hypoxia inducible factor-1 $\alpha$ (HIF-1 $\alpha$ ) in isolated retina; secondary anti-body is rodaminate. Presence of hypoxia after treatment with metilcellulose (A and B). Magnification 8 x. Scale bar: $200 \mu \mathrm{m}$. 
periphery, respectively; while their mean length was $26.23 \pm 6.11,30.32 \pm 3.58$, and $16.84 \pm 8.84 \mathrm{~mm}$ (Figure 5 ). $\mathrm{In} \mathrm{IB}_{4}$-labelled eyecup sections the mean number of vessel profiles found in each millimetre of retinal surface was $13.65 \pm 3.32$ for the superficial plexus, $17.67 \pm 5.15$ for the deep plexus and $7.44 \pm 1.57$ for the connecting layer (Figure 6).

In MTC-treated eyes, in angiographic specimens vascular area and vessels length appeared increased over control values in the whole retina, with the exception of the optic nerve-adjacent area. The mean area of retinal vessels measured in $1 \mathrm{~mm}^{2}$ of retinal surface was $0.14 \pm 0.08,0.16 \pm 0.09$, and $0.14 \pm 0.09 \mathrm{~mm}^{2}$ in the proximal, mid and far-periphery, respectively; while their mean length was $29.5 \pm 7.4$, $39 \pm 3.11$, and $26.5 \pm 6.21$ (Figure 5).

In $\mathrm{IB}_{4}$-labelled eye-cup sections the mean number of vessel profiles belonging to the superficial plexus was unchanged with respect to control, while highly significant increases over the normal values were shown by vessels of connecting layer and deep plexus $(\mathrm{P}<0.01)$. The mean number of vessels profiles found in each millimetre of retinal surface was $15.2 \pm 2.33$ for the superficial plexus, $9.94 \pm 1.86$ for the deep plexus and $22.55 \pm 1.43$ for the connecting layer (Figure 6). Similar results were obtained when vascular profiles were separately counted in parasagittal and peripheral retinal sections. An important hypoxia was demonstrated through the expression of HIF-1 in the eye-cups labelled with antibodies (Figures 7 A, B).

\section{Discussion}

Purpose of this study was to evaluate the degenerative effects on the retina and eye-cup sections after experimental induction of acute ocular hypertension on animal models.

The IOP (normal value $\sim 12 \mathrm{mmHg}$ ) sharply increased $(\sim 60 \mathrm{mmHg})$ after $3 \mathrm{~min}$ of MTC injection, due to the progressive occlusion of trabeculate and Schlemm's canal, and it decreased to $25 \mathrm{mmHg} 10 \mathrm{~h}$ after the injection, remaining stable for at least 3 days. ${ }^{3}$ IOP increase is caused by two probable parameters: i) Oxygen lower supply and ii) mechanic damage. As for the first parameter, the vascular alterations described as well as the observed capillary net coarser than control, the appeared heavily altered radial venules, the extremely dilated vascular segments, the non-vascularized regions and the focal points of FITC thickening in arterioles (Figures 2 B,C,D), can be considered as direct consequences of pressure-dependent blood flow impairments and therefore responsible of an important hypoxia (Figures 7 A,B). In fact, intra-vitreous vascular extensions and/or FITC leakage were never observed since VEGF immunoreactivity was similar to controls.

As for the second parameter, in MTC-injected animals the increase of GFAP expression and the presence of immunoreacted cellular expansions, perpendicularly oriented to retinal surface, could testify the activation of astrocytes and Müller cells. This process could cause a direct nerve fibers compression, which could arrest the axonal flow of several neuronal mediators, such as nerve growth factor (NGF), brain-derived neurotrophic factor (BDNF) and neurotrophin (NT-3/4/5). ${ }^{34-40}$ Lack of this mediators would stimulate the apoptotic process on ganglion cells. Therefore, the progressive collapse of the lamina cribrosa and the following compression of nerve fibers might arrest the axonal flow in MTC-injected animals. The increase of IOP will finally produce a constriction of preliminary optic nerve head vessels bringing to a focal ischemia.

In this model of MTC-induced intraocular hypertension we described both glial and vascular variations which are functionally related. In particular, local alterations in oxygen level, caused by pressure-induced morpho-physiologic disorders in vascular net, could produce the glial activation followed by neuronal affections. ${ }^{5-7,22}$ On the other hand, astrocytes and vascular endothelial cells, known as the main components of haemato-retinic barrier, ${ }^{39,40}$ are able to produce vasoactive factors, such as endotelin (ET-1), ${ }^{41}$ nitric oxide (N0), ${ }^{42}$ prostacyclins (PGI2) ${ }^{43}$ and VEGF. ${ }^{27,44,45}$ In particular, ET-1 has a vasoconstrictive action and several researchers recognized its increase in aqueous humour of glaucomatous eyes ${ }^{46}$ while NO is a vasodilator and it decreases because of a vascular endothelium dysfunction. ${ }^{42,47}$ Both ET1 and NO should bring to a chronic ischemia of the optic nerve and to a contraction of trabecular myofibrils, followed by a further IOP increase. The ET-1 is also able to stimulate astroglial proliferation, to sensitize amacrine cells to the toxic action of glutamate and to damage ganglion cells. ${ }^{14,41,42,46-54}$

The data on the interactions among glia, vessels and neurons obtained in this experimental model, might be useful to evaluate if also in retina of glaucoma-affected patients the activation of vessel-adjacent glial cells might play several key roles in following neuronal dysfunction. Both in control and MTCtreated eyes, VEGF localization was highly expressed in Müller, ganglion and inner nuclear layer cells. The localization found in rats control eyes, being coincident with that reported for normal monkeys and humans, ${ }^{55,56}$ confirms that in retina of adult mammals VEGF is basically expressed by several cell types. In the fully developed retinal vasculature the growth factor can be hypothesized to act as a survival factor for endothelial cells and known as the main cause of endothelial cell proliferation in growing vessels. ${ }^{25}$ In retina of MTCtreated the moderate variations to visualize VEGF localization demonstrate that its expression was not heavily altered $72 \mathrm{~h}$ after MTCinjection because maybe the nuclear activation, which is necessary to increase the production and the storage of VEGF in tissues, may take more than $72 \mathrm{~h}$ of ocular hypertension. In conclusion, increase of IOP associated with the increase of vasoactive factors may cause an ischemic process which, together with mechanic damage, should lead to an apoptotic effect on ganglion cells and to the onset of the glaucomatous optic neuropathy.

Further studies, carried out at later stages after MTC injection, would allow a better evaluation of the actual significance of vascular remodelling and the interactions with both glia and neurons in animal model of ocular hypertension, which are useful especially for investigating the causes of glaucoma.

\section{References}

1. Friedman DS, Wilson MR, Liebmann JM, Fechtner RD, Weinreb RN. An evidence based assessment of risk factors for the progression of ocular hypertension and glaucoma. Am J Ophthalmol Rev 2004; 138:19-31.

2. Quigley HA, McKinnon SJ, Zack DJ, Pease ME, Kerrigan-Baumrind LA, Kerrigan FD, et al. Retrograde axonal transport of BDNF in retinal ganglion cell is blocked by acute IOP elevation in rats. Invest 0phthalmol Vis Sci 2000;41:3460-6.

3. Calandrella N, Scarsella G, Pescosolido N, Risuleo G. Degenerative and apoptotic events at retinal and optic nerve level after experimental Induction of ocular hypertension. Mol Cell Biochem 2007;301:15563.

4. Gariano RF, Gardner TW. Retinal angiogenesis in development and disease. Nature 2005;438:960-6.

5. Erickson PA, Fisher SK, Guerin CJ, Anderson DH, Kaska DD. Glial fibrillary acidic protein increases in Müller cells after retinal detachment. Exp Eye Res 1987;44:37-48.

6. Okada M, Matsumura M, Ogino N, Honda Y. Müller cells in detached human retina express glial fibrillare acidic protein and vimentin. Graefes Arch Clin Exp Ophthalomol 1990;228:467-74.

7. Mizutani M, Gerhardinger C, Lorenzi M. Müller cell changes in human diabetic retinopathy. Diabetes 1998;47:445-9.

8. Guidry C, Medeiros NE, Curcio CA. 
Phenotypic variation of retinal pigment epithelium in age-related macular degeneration. Invest Ophthalmol Vis Sci 2002;43:267-73.

9. Tanihara H, Hangai M, Sawaguchi S, Abe H, Kageyama M, Nakazawa F, et al. Upregulation of glial fibrillary acidic protein in the retina of primate eyes with experimental glaucoma. Arch Ophthalmol 1997;115:752-6.

10. Wang X, Tay SS, Ng YK. An immunohistochemical study of neuronal and glial cell reactions in retinae of rats with experimental glaucoma. Exp Brain Res 2000; 132:476-84.

11. Wang L, Cioffi GA, Cull G, Dong J, Fortune B. Immunohistologic evidence for retinal glial cell changes in human glaucoma Invest Ophthalmol Vis Sci 2002;43:108894.

12. Roque RS, Caldwell RB. Müller cell changes precedes vascularization of the pigment epithelium in the dystrophic rat retina. Glia 1990;3:464-75.

13. DiLoreto DA, Martzen MR, Del Cerro C, Coleman PD, Del Cerro M. Müller cell changes precede photoreceptor cell degeneration in the age-related retinal degeneration of the Fischer 344 rat. Brain Res 1995;698:1-14.

14. Lieth E, Barber AJ, Xu B, Dice C, Ratz MJ, Tanase D, et al. Glial reactivity and impaired glutamate metabolism in shortterm experimental diabetic retinopathy. Diabetes 1998;47:815-20.

15. Osborne NN, Block F, Sontag KH. Reduction of ocular blood flow results in glial fibrillary acidic protein (GFAP) expression in rat retinal Muller cells. Vis Neurosci 1991;7:637-9.

16. Humphrey MF, Constable IJ, Chu Y, Wiffen S. A quantitative study of the lateral spread of Müller cell responses to retinal lesions in the rabbit. J Comp Neurol 1993;334:54558.

17. Nishiyama T, Nishukawa S, Hiroshi, Tomita, Tamai M. Müller cells in the preconditioned retinal ischemic injury rat Tohoku J Exp Med 2000;191:221-32.

18. Hernandez MR. The optic nerve head in glaucoma: role of astrocytes in tissue remodeling. Prog Retin Eye Res 2000;19:297-321.

19. Tezel G, Hernandez R, Wax MB. Immunostaining of heat shock protein in the retina and optic nerve head of normal and glaucomatous eyes. Arch Ophthalmol 2000;118:511-8.

20. Yuang L, Neufeld AH. Tumor necrosis factor-alpha: a potentially neurodestructive cytokine produced by glia in the human glaucomatous optic nerve head. Glia 2000;32:42-50
21. Tezel G, Hernandez MR, Wax MB. In vitro evaluation of reactive astrocyte migration, a component of tissue remodeling in glaucomatous optic nerve head astrocytes. Glia 2001;34:178-89.

22. Tezel G, Chauhan BC, LeBlanc RP, Wax MB. Immunohistochemical assessment of glial mitogen-activated protein kinase activation in glaucoma. Invest Ophthalmol Vis Sci 2003;44:3025-33.

23. Klagsbrun M, Moses MA. Molecular angiogenesis. Chem Biol 1999;6:R217-24.

24. Hughes $S$, Yang $H$, Chan-Ling $T$. Vascularization of the human fetal retina: roles of vasculogenesis and angiogenesis. Invest Ophthalmol Vis Sci 2000;41:121728.

25. Gerhardt H, Golding M, Fruttiger M, Ruhrberg C, Lundkvist A, Abramsson A, et al. VEGF guides angiogenic sprouting utilizing endothelial tip cell filopodia. J Cell Biol 2003;161:1163-77.

26. Stone J, Itin A, Alon T, Pe'er J, Gnessin H, Chan-Ling T, et al. Development of retinal vasculature is mediated by hypoxia-induced vascular endothelial growth factor (VEGF) expression by neuroglia. J Neurosci 1995;15:4738-47.

27. Provis JM, Leech J, Diaz CM, Penfold PL, Stone J, Keshet E. Development of the human retinal vasculature: cellular relations and VEGF expression. Exp Eye Res 1997;65:555-68.

28. McIntosh LC, Muckersie L, Forrester JV. Retinal capillary endothelial cells prefer different substrates for growth and migration. Tissue Cell 1988:20;193-209.

29. Pierce EA, Avery RL, Foley ED, Aiello LP, Smith LE. Vascular endothelial growth factor/vascular permeability factor expression in a mouse model of retinal neovascularization. Proc Natl Acad Sci USA 1995;92:905-9.

30. Donahue ML, Phelps DL, Watkins RH, Lo Monaco MB, Horowitz S. Retinal vascular endothelial growth factor (VEGF) mRNA expression is altered in relation to neovascularization in oxygen induced retinopathy. Curr Eye Res 1996;15:175-84.

31. Witmer AN, Blaauwgeers HG, Weich HA, Alitalo K, Vrensen GF, Schlingemann RO. Altered expression patterns of VEGF receptors in human diabetic retina and in experimental VEGF-induced retinopathy in monkey. Invest Ophthalmol Vis Sci 2002;43:849-57.

32. Hu DN, Ritch R, Liebmann J, Liu Y, Cheng B, Hu MS. Vascular Endothelial Growth Factor is increased in aqueous humor of glaucomatous eyes. J Glaucoma 2002; 11:406-10.

33. D'Amato R, Wesolowski E, Smith LE. Microscopic visualization of the retina by angiography with high-molecular-weight fluorescein-labeled dextrans in the mouse. Microvasc Res 1993;46:135-42.

34. Fujita Y, Imagawa T, Uehara M. Fine structure of the retino-optic nerve junction in the chicken. Tissue Cell 2001;33:129-34.

35. Lambert WS, Clark AF, Wordinger RJ. Effect of exogenous neurotrophins on Trk receptor phosphorylation, cell proliferation, and neurotrophin secretion by cells isolated from the human lamina cribrosa. Mol Vis 2004;10:289-96.

36. Agarwal N, Agarwal R, Kumar DM, Ondricek A, Clark AF, Wordinger RJ, et al. Comparison of expression profile of neurotrophins and their receptors in primary and transformed rat retinal ganglion cells. Mol Vis 2007;13:1311-8.

37. Bessero AC, Clarke PG. Neuroprotection for optic nerve disorders. Curr Opin Neurol. 2010;23:10-5.

38. Lorber B, Guidi A, Fawcett JW, Martin KR. Activated retinal glia mediated axon regeneration in experimental glaucoma. Neurobiol Dis. 2012;45:243-52.

39. Pescosolido N, Pascarella A, Scarsella G, Tafani M, Stefanini S, Nebbioso M. Topotecan hydrochloride effects on retinal vessels in newborn rats. Histol Histopathol. 2012;27:497-506.

40. Pardridge WM. Blood-brain barrier biology and methodology. J Neurovirol 1999;5:55669 .

41. Ehrenreich H, Löffler BM, Hasselblatt M, Langen H, Oldenburg J, Subkowski T, et al. Endothelin converting enzyme activity in primary rat astrocytes is modulated by endothelin B receptor. Biochem Biophys Res Commun 1999;261:149-55.

42. Neufeld AH, Hernandez MR, Gonzalez M. Nitric oxide synthase in the human glaucomatous optic nerve head. Arch Ophthalmol 1997;115:497-503.

43. Mori A, Saito M, Sakamoto K, Nakahara T, Ishii K. Intravenously administered vasodilatory prostaglandins increase retinal and choroidal blood flow in rats. $J$ Pharmacol Sci. 2007;103:103-12.

44. Behzadian MA, Wang XL, Al-Shabrawey M, Caldwell RB. Effects of hypoxia on glial cell expression of angiogenesis-regulating factors VEGF and TGF-beta. Glia 1998;24:21625.

45. Zhao W, Shen H, Yuan F, Li G, Sun Y, Shi Z, et al. Induction stage-dependent expression of vascular endothelial growth factor and aquaporin-1 in diethylstilbestrol-treated rat pituitary. Eur J Histochem 2009; 53:53-60.

46. Prasanna G, Krishnamoorthy R, Yorio T. Endothelin, astrocytes and glaucoma. Exp Eye Res. 2011;93:170-7.

47. Dai Y, Weinreb RN, Kim KY, Nguyen D, 
Park S, Sun X, et al. Inducible nitric oxide synthase-mediated alteration of mitochondrial OPA1 expression in ocular hypertensive rats. Invest Ophthalmol Vis Sci 2011;52:2468-76.

48. Kaiser HJ, Flammer J, Wenk M, Lüscher T. Endothelin-1 plasma levels in normal-tension glaucoma: abnormal response to postural changes. Graefes Arch Clin Exp Ophthalmol 1995;233:484-8.

49. Cellini M, Possati GL, Profazio V, Sbrocca M, Caramazza N, Caramazza R. Color Doppler imaging and plasma levels of endothelin-1 in low-tension glaucoma. Acta Ophthalmol Scand Suppl 1997;224:113 .

50. Dkhissi 0, Chanut E, Wasowicz M, Savoldelli M, Nguyen-Legros J, Minvielle F, et al. Retinal TUNEL-positive cells and high glutamate levels in vitreous humor of mutant quail with a glaucoma-like disorder. Invest Ophthalmol Vis Sci 1999;40:990-5.

51. Prasanna G, Krishnamoorthy R, Clark AF, Wordinger RJ, Yorio T. Human optic nerve head astrocytes as a target for endothelin1. Invest Ophthalmol Vis Sci 2002;43:270413.

52. Desai D, He S, Yorio T, Krishnamoorthy RR, Prasanna G. Hypoxia augments TNFalpha-mediated endothelin-1 release and cell proliferation in human optic nerve head astrocytes. Biochem Biophys Res Commun 2004;318:642-8.

53. Prasanna G, Hulet C, Desai D, Krishnamoorthy RR, Narayan S, Brun AM, et al. Effect of elevated intraocular pressure on endothelin-1 in a rat model of glaucoma. Pharmacol Res 2005;51:41-50.

54. Zhang S, Wang H, Lu Q, Qing G, Wang N, Wang Y, et al. Detection of early neuron degeneration and accompanying glial responses in the visual pathway in a rat model of acute intraocular hypertension. Brain Res 2009;1303:131-43.

55. Kim I, Ryan AM, Rohan R, Amano S, Agular $\mathrm{S}$, Miller JW, et al. Constitutive expression of VEGF, VEGFR-1, and VEGFR-2 in normal eyes. Invest Ophthalmol Vis Sci 1999;40:2115-21.

56. Famiglietti EV, Stopa EG, McGookin ED, Song P, LeBlanc V, Streeten BW. Immunocytochemical localization of vascular endothelial growth factor in neurons and glial cells of human retina. Brain Res 2003;969:195-204. 